Pol. J. Food Nutr. Sci., 2019, Vol. 69, No. 1, pp. 63-70

DOI: $10.31883 /$ pjfns-2019-0006 http://journal.pan.olsztyn.pl

Original research article

Section: Food Quality and Functionality

\title{
Post-Harvest Warehouse Management of Actinidia arguta Fruits
}

\author{
Nicole Roberta Giuggioli*, Rossella Briano, Claudio Baudino, Cristiana Peano
}

Department of Agricultural Forest and Food Sciences (DISAFA), University

of Torino, Largo Braccini 2, Grugliasco (TO) 10095, Italy

Key words: storage, wrap film, baby kiwifruit, cultivar

In the baby kiwifruit food chain, the extent of losses caused by high perishability of the edible skin is a barrier for these fruit's position in the fresh market. Thus, maintaining the overall quality in the warehouse is fundamental for the market channel. The wrapping technique with a stretch film represents a fine opportunity for maintaining fruit quality. Hortgem Rua ${ }^{\circledR}$ and Hortgem Tahi ${ }^{\circledR}$ cultivars of kiwifruits were evaluated during storage at $1 \pm 1^{\circ} \mathrm{C}$ for up to 60 days. The stretch wrap film used to protect the fruit has shown to limit the weight loss maintained by the pulp of both cultivars that were firmer $\left(2.39 \mathrm{~N}\right.$ and $2.13 \mathrm{~N}$ ) and had lower gumminess values (280.92 and 213.57 for Hortgem Rua ${ }^{\circledR}$ and Hortgem Tahi ${ }^{\circledR}$, respectively). Considering sensorial attributes, the wrapped samples also maintained overall quality, especially in terms of fruit colour (luminosity), consistency and taste.

\section{INTRODUCTION}

It is well-recognized that storage practices can widely influence the quality of fruits in the post-harvest chain [Wang et al., 2015]. The research plays an important role, especially for new fruit cultivars, including Actinidia arguta (Siebold et Zucc.) Planch. ex Miq. Among fresh and perishable fruits, the baby kiwifruits are consumed without peeling, similarly to berries. Due to the rapid transformation to softening, skin wrinkling, water loss and fruit decay [Latocha et al., 2014], baby kiwifruits require efficient storage tools in the supply chain management [Giuggioli et al., 2017; White et al., 2005]. When compared to other Actinidiaceae (A. deliciosa, and A. chinensis), the baby kiwifruit can be stored for a shorter period of time, namely for 1-2 months at $0^{\circ} \mathrm{C}$ [Baudino et al., 2017; Lim et al., 2016; Strik \& Hummer, 2006]. Previous studies have attempted to identify the best method for increasing the shelf-life, by utilizing 1-methylcyclopropene (1-MCP) [Wang et al., 2015], edible coating [Fisk et al., 2008; Kaya et al., 2016] or by identifying the optimal harvest date for improving storability [Oh et al., 2017]. According to the current social and economic scenarios, the driver of the innovation and the key point to improve the performance of all preserving techniques is the sustainability requirement to satisfy the competitiveness asset of the supply chain. In addition, it is reported that some storage methods involving the management of the atmosphere in the storage room (controlled atmosphere) are more expensive when compared to other tools [Wang et al., 2015]. The warehouse storage represents a critical point in the fresh fruit supply chain

\footnotetext{
* Corresponding Author: Tel.: +39.011.670.8646; Fax +39.011.670.8658;

E-mail: nicole.giuggioli@unito.it
}

[Peano et al., 2017], but the use of packaging and pallet bags strategies has been reported just as useful to maintain the safety and quality of different species, such as blueberry, strawberry, raspberry, and plums [Peano et al., 2015, 2017; DeEll, 2002].

With the pallet bag, it is possible to store large quantities of products and facilitate their transfer from the warehouse to a truck or a container for shipment [Bouchery et al., 2017]. Additionally, using pallet bags to store different kinds of fruits in the same cold-room helps to avoid possible cross-contaminations with other products. While the pallet bag approach has its benefits to the storage of kiwifruit, the stretch wrap film in the warehouse is easier to manage. The pallet bag system, for example, requires the use of a plastic bag, a vacuum system, and a $\mathrm{CO}_{2}$ injection if the products need a modified atmosphere storage, hence the use of a stretch wrap film could be promising and more economical in terms of cost and time.

Considering the importance of packaging storage techniques and the limited studies about the effect of this practice in the post-harvest storage warehouse of Actinidia arguta, the goal of the present research was to evaluate the effects of the wrapping technique with a stretch film. This was based on an easy and economic tool used to preserve the quality traits, phenolics content, and textural parameters of two different baby kiwifruit cultivars (Hortgem Rua ${ }^{\oplus}$ and Hortgem Tahi ${ }^{\circledR}$ ) stored for up to 60 days.

\section{MATERIALS AND METHODS}

Fruit source, experimental design and sampling procedure

The baby kiwifruits orchard is located in Revello $(\mathrm{Cu}-$ neo, Piedmont, Italy). The fruits of Actinidia arguta (Siebold 
et Zucc.) were from two different cultivars: Hortgem Rua ${ }^{\circledR}$ and Hortgem Tahi $^{\circledR}$ marketed with the NERGI ${ }^{\circledR}$ brand [Baudino et al., 2017]. They are newly patented cultivars originating from New Zealand [McNeilage et al., 2003, 2004]. All fruits from each cultivar were collected at the harvesting maturity stage and stored inside a plastic fruit box $(270 \times 370 \times$ $165 \mathrm{~cm}$ ) (CPR System, Bologna, Italy). The fruits were transported to the Agrifrutta Cooperative warehouse (Peveragno, Cuneo, Piedmont, Italy) for storage at $1{ }^{\circ} \mathrm{C}$ which rapidly decreased the core temperature of the fruits. Selected fruits of medium weights: $10.1-15.0 \mathrm{~g}$ for Hortgem Tahi ${ }^{\circledR}$ and 13.1$-15.0 \mathrm{~g}$ for Hortgem Rua ${ }^{\circledR}$, were packed inside a plastic punnet with lids made from R-PET material (INFIA s.r.l., Cesena, Italy). Punnet dimensions were $17.2 \times 13.2 \times 4.0 \mathrm{~cm}$ and contained $0.125 \mathrm{~kg}$ of fruit; lid dimensions were $17.8 \times 13.6 \mathrm{~cm}$. The experimental storage unit was a mini pallet loaded with 20 stacked crates wrapped with a polyethylene stretch film (Retarder s.r.l., Cuneo, Italy). The stretch wrap film was used to create a barrier protection against the cool air forced into the room. It was not hermetically sealed and, for this reason, changes in the atmosphere were not expected. Control samples were maintained in a normal atmosphere in a controlled cold room $\left(1 \pm 1^{\circ} \mathrm{C} ; 95 \%\right.$ humidity). Three replicates were considered for each control. All fruits were stored for up to 60 days. Quality control was performed at the day of package processing (day 0) and after 20, 40, and 60 days of storage. At each time-point, 20 punnets (control and stretch) were randomly selected and the following parameters were determined: weight loss, quality indicators (total soluble solids, total acidity, and dry matter), total color difference, textural indicators (firmness and gumminess), and total phenolics content. A sensory analysis was also performed to better judge the fruits.

\section{Weight loss, quality parameters, and total colour difference}

Weight loss (\%) was determined using an electronic balance (model SE622, VWR Science Education, Radnor, Pennsylvania, USA), with a $0.01 \mathrm{~g}$ accuracy. The weight was monitored throughout the storage time and it was calculated as the difference between the initial and final punnet weights. Content of total soluble solids (TSS) was determined with a digital refractometer Atago® Pal-1 (Atago Co. Ltd., Tokyo, Japan) and expressed as ${ }^{\circ}$ Brix. For each quality control, the instrument was calibrated with distilled water. The total acidity (TA) was measured using an automatic titrator (Titritino 702, Methrom, Herisav, Switzerland) and determined potentiometrically using $0.1 \mathrm{~N} \mathrm{NaOH}$ to the end point of 8.1 in $5 \mathrm{~mL}$ of juice diluted in $25 \mathrm{~mL}$ of distilled water. The raw juice obtained by squeezing fruits in a mixer (Moulinex-Ju2000) was centrifuged at $1000 \mathrm{rpm}$ for $5 \mathrm{~min}$ using a Rotofix 32-A Centrifuge (VWR, Milan, Italy). The supernatants were used for analyses. Results were expressed as g of citric acid equivalents per $100 \mathrm{~mL}$ of juice (g CA/100 mL) [Allegra et al., 2017; Briano et al., 2015].

Dry matter (DM) content of baby kiwifruits was measured in 10 whole fruits. The fruits were placed in an oven at $70 \pm 2^{\circ} \mathrm{C}$ for $24 \mathrm{~h}$. Their initial and final weights were measured using an electronic balance and the value was expressed as $\mathrm{g} / 100 \mathrm{~g}$, according to McGlone et al. [2003].
Color parameters were quantified in the $L^{*}, a^{*}, b^{*}$ color space. $L^{*}$ refers to the lightness and ranged from $L^{*}=0$ (black) to $L^{*}=100$ (white). Negative and positive values of $a^{*}$ indicate green and red colour, respectively, while positive and negative $b^{*}$ indicate yellow and blue color, respectively [McGuire, 1992]. Color was assessed for 20 fruits in the middle part of the fruit using a tristimulus colour analyser (model CR-400, Konica Minolta, Langenhagen, Germany).

Change in fruit colour during the storage period was reported by the total colour difference $\left(\Delta E^{*}\right)$ index (equation 1), based on the evaluation of colour changes from the beginning of day 0 (L0, a0, b0) [Alexandre et al., 2012]:

$$
\Delta E^{*}=\left(\Delta \mathrm{a}^{* 2}+\Delta \mathrm{b}^{* 2}+\Delta \mathrm{L}^{* 2}\right)^{1 / 2}
$$

(Equation 1)

\section{Textural parameters}

A texture profile analysis (TPA) performed with a Texture Analyser TA.XT.PLUS (Stable Micro Systems, WINOPAL Forschungsbedarf GmbH, Steinheim, Austria) (30 Kilo Load Cell) was used to evaluate the firmness $(\mathrm{N})$ and the gumminess ( $\left.\mathrm{g}^{*} \mathrm{~s}\right)$ parameters. A compression test was performed with a $30-\mathrm{mm}$ aluminium flat tipped probe $(\mathrm{P} / 3)$ to a $10 \%$ strain, with a pre-test speed of $1 \mathrm{~mm} / \mathrm{s}$, test speed $1 \mathrm{~mm} / \mathrm{s}$, post-test speed $5 \mathrm{~mm} / \mathrm{s}$, and $5 \mathrm{~g}$ trigger force. In the case of gumminess, a $75 \mathrm{~mm}$ aluminium compression plate $(\mathrm{P} / 75)$ was used and the following parameters were applied: strain (25\%), pretest speed $(1 \mathrm{~mm} / \mathrm{s})$, test-speed $(5 \mathrm{~mm} / \mathrm{s})$, and trigger force (5 g).

\section{Total phenolics content}

Total phenolics content (TPC) of extracts of kiwifruits was determined. Fruits $(10 \mathrm{~g})$ were added to $25 \mathrm{~mL}$ of an extraction mixture which contained $500 \mathrm{~mL}$ of methanol, $23.8 \mathrm{~mL}$ of de-ionized water, and $1.4 \mathrm{~mL}$ of $37 \%$ hydrochloric acid. The mixture was kept in dark at room temperature for $1 \mathrm{~h}$ and afterwards thoroughly homogenized for 2 min with an ULTRA TURRAX (IKA, Staufen, Germany) and centrifuged for $15 \mathrm{~min}$ at $3000 \mathrm{rpm}$. The supernatant was transferred into glass test-tubes and stored at $-20^{\circ} \mathrm{C}$ until analyzed. The total phenolics content of samples was measured using the Folin $\&$ Ciocalteu phenol reagent (Merck KGaA, Darmstadt, Germany). The absorbance of the blue color developed was measured at $765 \mathrm{~nm}$ following the method of Slinkard \& Singleton [1977]. The results were expressed as mg of gallic acid equivalents per $100 \mathrm{~g}$ of fresh fruits (mgGAE/100 g).

\section{Sensory analysis}

The quality of baby kiwifruit was evaluated by means of sensory analysis, involving 10 panellists previously trained using commercial samples. Panellists received 10 whole fruits for each sample and provided descriptions of their taste, appearance, overall acceptability, luminosity (one of the colour parameters), and consistency.

Evaluations took place in individual testing booths at room temperature. All the attributes were evaluated by using a 5 -point scale $(5=$ excellent, $4=\operatorname{good}, 3=$ fair, $2=$ poor, and $1=$ unusable) which was adopted from Meilgaard et al. [2006]. 


\section{Statistical analysis}

All statistical analyses were performed using SPSS Statistics 24 software package (2017, IBM, Milan, Italy) for Mac. All data sets (cultivar Hortgem Rua ${ }^{\circledR}$ and Hortgem Tahi ${ }^{\circledR}$ ) for the quality analysis were subjected to the analysis of variance (ANOVA) with Tukey's post hoc test. A statistically significant difference was indicated by $\mathrm{P} \leq 0.05$. A principal component analysis (PCA) with Varimax rotation with Kaiser normalization was entered to underline the relationships between the different qualitative parameters measured and results of the sensory analysis. The PCA was performed using standardized data due to the reduction of the dimensionality in the multivariate data. Two PCAs were obtained for each cultivar, i.e. Hortgem Rua ${ }^{\circledR}$ and Hortgem Tahi ${ }^{\circledR}$.

\section{RESULTS AND DISCUSSION}

\section{Weight loss}

The baby kiwifruit weight loss is reported in Figure 1. The loss in weight was progressively increasing with the post-harvest time and statistically significant differences were observed for each sample during the storage time. Samples of both cultivars stored in the mini pallet wrapped with the stretch film had limited weight loss of the product when compared to the control samples. The control samples of both cultivars showed a similar trend of losing the maximum weight at the end of the storage time $\left(9.03 \%\right.$ and $9.64 \%$ for Hortgem Rua ${ }^{\circledR}$ and Hortgem Tahi ${ }^{\circledR}$, respectively). The best performance of the stretch wrap film to control fruits management was observed for the Hortgem Tahi ${ }^{\circledR}$. In fact, at the end of the 60-day storage period, the weight loss was only $3.57 \%$, while at the same time point, the weight loss noted in fruits of cv. Hortgem Rua ${ }^{\circledR}$ reached $6.40 \%$. Considering the limit of the commerciality at $6 \%$ weight loss [Briano et al., 2017; Almenar et al., 2007], the use of wrapped mini pallet had a positive effect upon fruit management and on reducing peel wrinkling already after 20 days and up to 60 days of storage in the warehouse.

A

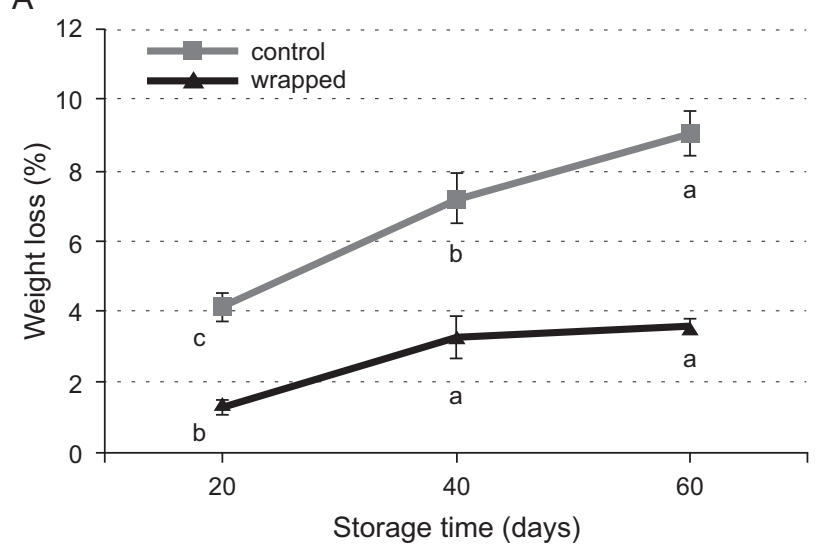

\section{Quality parameters}

Changes in fruit quality parameters during storage were evaluated by measuring total acidity (TA) and determining contents of total soluble solids (TSS) and dry matter (DM) (Table 1). For the collected samples wrapped with stretch film, it was possible to observe an increase in the TSS concentration during the storage time due to the weight loss of fruits. The highest TSS values were observed for all fruits at the end of the 60-day storage period. Effects resulting from storage time and different management in the warehouse on TA were similar for both tested cultivars. Statistically significant differences $(\mathrm{P}<0.05)$ were observed during the storage time and a decrease of values was observed for all samples. For both cultivars, the lowest fruit acidity was reported at the end of the storage time for the samples maintained in the stretch wrap film.

The storability of the kiwifruits is well-recognized to be correlated with the DM content [Harker et al., 2009; Jordan et al., 2000]. Statistically significant differences $(\mathrm{P}<0.05)$ were observed during the storage time for fruits of both cultivars and for each sample. A general decrease in DM content was observed for all samples and the lowest DM content was achieved at the end of the storage time for all baby kiwifruits. Similar values were observed among wrapped fruits and control ones at each control time, suggesting the limited influence of the stretch film on maintaining high levels of DM content during storage

\section{Total color difference}

The external aspect and colour are important attributes for the edibility of these fruits that are eaten with the peel. The total colour difference $\left(\Delta E^{*}\right)$ index, which is a combination of $L$, $a$ and $b$ values, was used to evaluate the discoloration of fruits (Figure 2). The $\Delta E^{*}$ value increased statistically in the storage time, meaning a progressive ripening of the fruits for all the samples, but this trend was limited for all fruits wrapped with the stretch wrap film. At the end of storage time, the minimum $\Delta E^{*}$ value was achieved for the wrapped samples of the cv. Hortgem Rua ${ }^{\circledR}$ (11.80). Due to the best maintenance of weight loss (water content), these fruits actually maintained the highest luminosity (data not shown). Wrapped samples

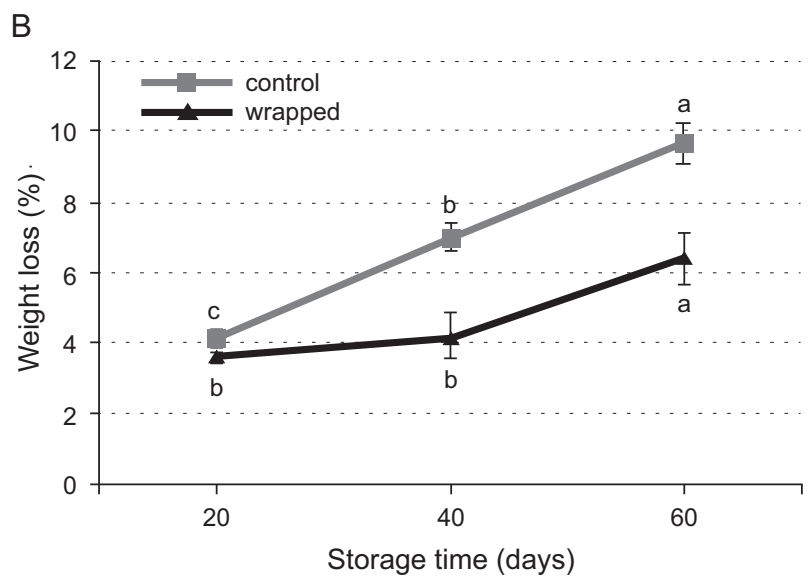

FIGURE 1. Weight loss of baby kiwifruits of Hortgem Rua ${ }^{\circledast}$ (A) and Hortgem Tahi ${ }^{\circledast}$ (B) cultivars during storage. All data are expressed as average value and the standard error as bars. Different letters on the line indicate significant differences among every harvesting time $(\mathrm{P}<0.05)$. 
TABLE 1. Total soluble solids (TSS), total acidity (TA), and dry matter (DM) of the kiwifruits of Hortgem Rua ${ }^{\circledast}$ and Hortgem Tahi ${ }^{\circledast}$ cultivars during storage.

\begin{tabular}{|c|c|c|c|c|c|c|}
\hline \multirow{2}{*}{$\begin{array}{l}\text { Quality } \\
\text { parameters }\end{array}$} & \multirow{2}{*}{ Cultivar } & \multirow{2}{*}{ Samples } & \multicolumn{4}{|c|}{ Storage time (days) } \\
\hline & & & 0 & 20 & 40 & 60 \\
\hline \multirow{4}{*}{$\begin{array}{l}\text { TSS } \\
\left({ }^{\circ} \text { Brix }\right)\end{array}$} & \multirow{2}{*}{$\mathrm{Rua}^{\circledast}$} & Control & $9.90 \pm 0.10^{c}$ & $13.68 \pm 0.12^{\mathrm{b}}$ & $14.57 \pm 0.13^{\mathrm{a}}$ & $14.23 \pm 0.12^{\mathrm{a}}$ \\
\hline & & Wrapped & $9.90 \pm 0.10^{c}$ & $13.90 \pm 0.21^{\mathrm{b}}$ & $13.73 \pm 0.13^{b}$ & $14.96 \pm 0.12^{\mathrm{a}}$ \\
\hline & \multirow{2}{*}{ Thai $^{\circledR}$} & Control & $11.00 \pm 0.22^{\mathrm{c}}$ & $14.20 \pm 0.23^{\mathrm{b}}$ & $14.57 \pm 0.10^{\mathrm{b}}$ & $15.07 \pm 0.14^{\mathrm{a}}$ \\
\hline & & Wrapped & $11.00 \pm 0.22^{\mathrm{c}}$ & $14.87 \pm 0.14^{\mathrm{a}}$ & $13.73 \pm 0.31^{\mathrm{ab}}$ & $14.80 \pm 0.11^{\mathrm{a}}$ \\
\hline \multirow{4}{*}{$\begin{array}{l}\text { TA } \\
(\mathrm{g} \mathrm{CA} / 100 \mathrm{~mL})\end{array}$} & \multirow{2}{*}{ Rua $^{\circledast}$} & Control & $0.90 \pm 0.00^{\mathrm{a}}$ & $0.72 \pm 0.12^{\mathrm{b}}$ & $0.42 \pm 0.41^{\mathrm{c}}$ & $0.61 \pm 0.31^{\mathrm{c}}$ \\
\hline & & Wrapped & $0.90 \pm 0.00^{\mathrm{a}}$ & $0.64 \pm 0.22^{\mathrm{b}}$ & $0.58 \pm 0.01^{\mathrm{c}}$ & $0.59 \pm 0.11^{\mathrm{c}}$ \\
\hline & \multirow{2}{*}{ Thai $^{\circledR}$} & Control & $1.20 \pm 0.50^{\mathrm{a}}$ & $0.89 \pm 0.06^{\mathrm{b}}$ & $0.73 \pm 0.02^{\mathrm{c}}$ & $0.77 \pm 0.01^{\mathrm{c}}$ \\
\hline & & Wrapped & $1.20 \pm 0.50^{\mathrm{a}}$ & $0.92 \pm 0.52^{\mathrm{b}}$ & $0.92 \pm 0.55^{b}$ & $0.59 \pm 0.12^{\mathrm{c}}$ \\
\hline \multirow{4}{*}{$\begin{array}{l}\text { DM } \\
(\mathrm{g} / 100 \mathrm{~g})\end{array}$} & \multirow{2}{*}{$\mathrm{Rua}^{\circledast}$} & Control & $18.43 \pm 1.30^{\mathrm{a}}$ & $17.97 \pm 0,91^{\mathrm{a}}$ & $15.86 \pm 0.21^{\mathrm{b}}$ & $15.74 \pm 0.11^{b}$ \\
\hline & & Wrapped & $18.43 \pm 1.30^{\mathrm{a}}$ & $17.75 \pm 0.81^{\mathrm{a}}$ & $15.58 \pm 0.01^{\mathrm{b}}$ & $15.67 \pm 0.01^{\mathrm{b}}$ \\
\hline & \multirow{2}{*}{ Thai $^{\circledast}$} & Control & $19.39 \pm 1.10^{\mathrm{a}}$ & $19.88 \pm 0.02^{\mathrm{a}}$ & $18.25 \pm 0.11^{\mathrm{b}}$ & $16.53 \pm 0.36^{c}$ \\
\hline & & Wrapped & $19.39 \pm 1.10^{\mathrm{a}}$ & $18.11 \pm 0.20^{\mathrm{b}}$ & $17.15 \pm 0.62^{\mathrm{bc}}$ & $15.68 \pm 0.29^{\mathrm{d}}$ \\
\hline
\end{tabular}

All data are expressed as average values and the standard deviation determined for different fruits. Different letters within the same line indicate significant differences among every harvesting time (Tukey test; $\mathrm{p}<0.05$ ).

of the cv. Hortgem Tahi ${ }^{\circledR}$ have shown a higher loss in luminosity $\left(\Delta E^{*}\right.$ value of 15.10$)$ probably due to the higher development of anthocyanin during the ripening process, as suggested by previous studies [Montefiori et al., 2009].

\section{Textural parameters}

Although knowledge about the importance of the softening models of baby kiwifruits has increased in recent years [Giuggioli et al., 2017], the evolution of texture parameters under packaging conditions, such as the wrapping of mini pallet, has not been reported. Changes in firmness and gumminess values are reported in Table 2. As expected, a decrease in texture parameters of kiwifruits was observed in all samples of Hortgem Rua ${ }^{\circledR}$ and Hortgem Tahi ${ }^{\circledR}$ due to the dehydration associated with the storage time [Wang et al., 2015]. The best control of moisture loss was associated to the stretch wrap film that positively influenced the maintenance of fruit firmness. At each control time, the stretch film maintained a higher value of firmness for fruits of Hortgem Rua ${ }^{\circledR}$ than control samples. At the end of storage, 2.39 $\mathrm{N}$ of firmness was registered for the wrapped baby kiwifruits against $1.60 \mathrm{~N}$ of the unwrapped fruits. The same trend was observed for the cv. Hortgem Tahi ${ }^{\circledR}$ after 60 days of storage, where the average value of $2.13 \mathrm{~N}$ was observed against $1.79 \mathrm{~N}$. The evolution of the dimensional gumminess (hardness $\mathrm{x}$ cohesiveness) parameters was similar to the firmness behaviour of unwrapped samples of both cultivars (control) showing the lowest gumminess values, suggesting a strong correlation with the moisture content. After 60 days of storage, gumminess
A

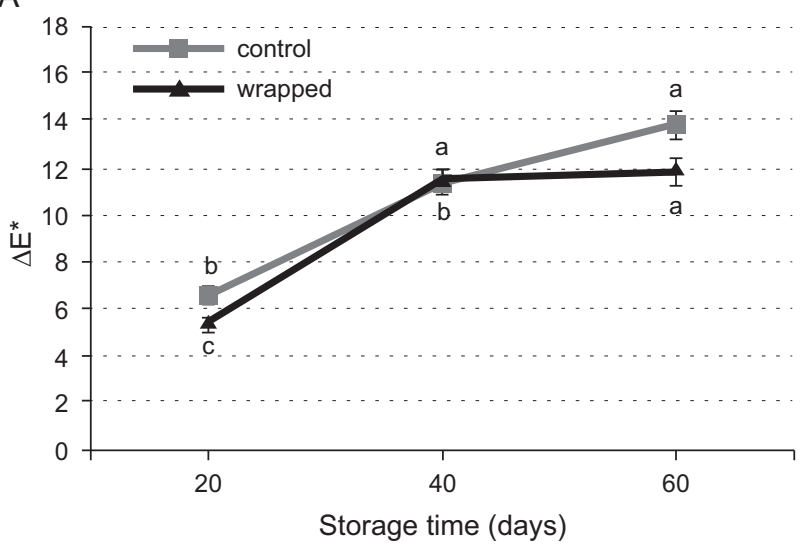

B

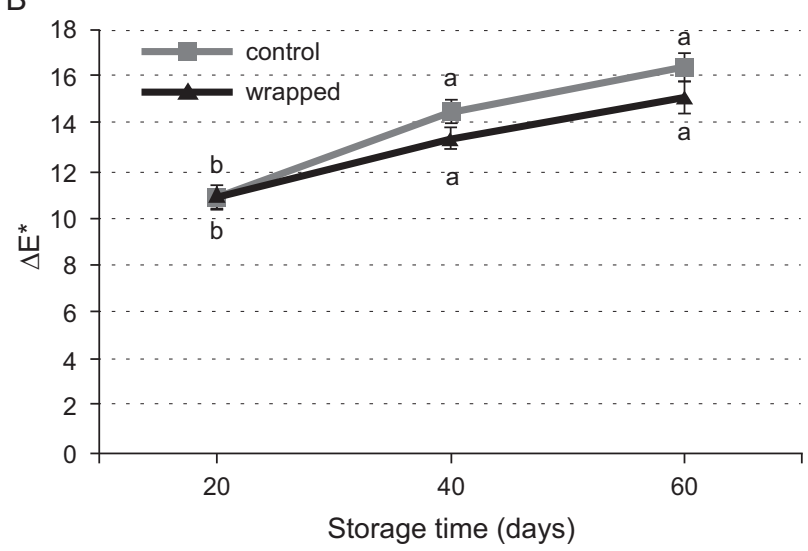

FIGURE 2. Evolution of the total colour difference $\left(\Delta E^{*}\right)$ of baby kiwifruits of Hortgem Rua ${ }^{\circledR}(\mathrm{A})$ and Hortgem Tahi ${ }^{\oplus}$ (B) cultivars during storage. All data are expressed as average value and the standard error as bars. Different letters on the line indicate significant differences among every harvesting time $(\mathrm{P}<0.05)$. 
TABLE 2. Textural parameters and total phenolic content (TPC) of the kiwifruits of Hortgem Rua ${ }^{\circledR}$ and Hortgem Tahi ${ }^{\circledR}$ cultivars during storage.

\begin{tabular}{|c|c|c|c|c|c|c|}
\hline \multirow{2}{*}{$\begin{array}{l}\text { Quality } \\
\text { parameters }\end{array}$} & \multirow{2}{*}{ Cultivar } & \multirow{2}{*}{ Samples } & \multicolumn{4}{|c|}{ Storage time (days) } \\
\hline & & & 0 & 20 & 40 & 60 \\
\hline \multirow{4}{*}{$\begin{array}{l}\text { Firmness } \\
(\mathrm{N})\end{array}$} & \multirow{2}{*}{ Rua $^{\circledast}$} & Control & $6.21 \pm 0.50^{\mathrm{a}}$ & $3.56 \pm 0.21^{\mathrm{b}}$ & $1.21 \pm 0.48^{c}$ & $1.60 \pm 0.19^{c}$ \\
\hline & & Wrapped & $6.21 \pm 0.50^{\mathrm{a}}$ & $3.84 \pm 0.13^{b}$ & $1.90 \pm 0.36^{c}$ & $2.39 \pm 0.19^{\mathrm{c}}$ \\
\hline & \multirow{2}{*}{ Thai $^{\circledR}$} & Control & $7.93 \pm 0.30^{\mathrm{a}}$ & $2.72 \pm 0.25^{\mathrm{b}}$ & $2.44 \pm 0.26^{\mathrm{c}}$ & $1.79 \pm 0.30^{c}$ \\
\hline & & Wrapped & $7.93 \pm 0.30^{\mathrm{a}}$ & $2.91 \pm 0.06^{\mathrm{b}}$ & $2.10 \pm 0.48^{b}$ & $2.13 \pm 0.48^{\mathrm{b}}$ \\
\hline \multirow{4}{*}{ Gumminess } & \multirow{2}{*}{$\mathrm{Rua}^{\circledast}$} & Control & $1152.90 \pm 1.71^{\mathrm{a}}$ & $681.95 \pm 0.86^{\mathrm{b}}$ & $502.10 \pm 0.46^{\mathrm{c}}$ & $213.57 \pm 1.11^{\mathrm{d}}$ \\
\hline & & Wrapped & $1152.90 \pm 1.71^{\mathrm{a}}$ & $656.66 \pm 0.52^{\mathrm{b}}$ & $531.77 \pm 0.96^{c}$ & $280.92 \pm 1.21^{\mathrm{d}}$ \\
\hline & \multirow{2}{*}{ Thai $^{\circledR}$} & Control & $936.32 \pm 1.43^{\mathrm{a}}$ & $800.27 \pm 1.01^{\mathrm{b}}$ & $416.97 \pm 1.85^{\mathrm{c}}$ & $211.08 \pm 0.91^{\mathrm{d}}$ \\
\hline & & Wrapped & $936.32 \pm 1.43^{\mathrm{a}}$ & $691.58 \pm 1.21^{\mathrm{b}}$ & $432.83 \pm 1.24 \mathrm{c}$ & $221.58 \pm 0.87^{\mathrm{d}}$ \\
\hline \multirow{4}{*}{$\begin{array}{l}\text { TPC } \\
(\mathrm{mgGAE} / 100 \mathrm{~g})\end{array}$} & \multirow{2}{*}{$\mathrm{Rua}^{\circledR}$} & Control & $189.90 \pm 1.32^{\mathrm{a}}$ & $190.90 \pm 0.91^{\mathrm{b}}$ & $167.01 \pm 2.50^{c}$ & $154.88 \pm 0.92^{\mathrm{d}}$ \\
\hline & & Wrapped & $189.90 \pm 1.32^{b}$ & $182.24 \pm 0.70^{\mathrm{b}}$ & $191.52 \pm 0.50^{\mathrm{b}}$ & $249.57 \pm 0.13^{\mathrm{a}}$ \\
\hline & \multirow{2}{*}{ Thai $^{\circledast}$} & Control & $187.51 \pm 0.91^{\mathrm{c}}$ & $225.13 \pm 0.11^{\mathrm{b}}$ & $291.81 \pm 0.10^{\mathrm{a}}$ & $298.79 \pm 0.57^{\mathrm{a}}$ \\
\hline & & Wrapped & $187.51 \pm 0.91^{\mathrm{b}}$ & $220.72 \pm 0.81^{b}$ & $280.50 \pm 0.20^{\mathrm{a}}$ & $290.50 \pm 0.48^{\mathrm{a}}$ \\
\hline
\end{tabular}

All data are expressed as average values and the standard deviation determined for different fruits. Different letters within the same line indicate significant differences among every harvesting time (Tukey test; $p<0.05$ ).

of fruits of cv. Hortgem Rua ${ }^{\circledR}$ and Hortgem Tahi ${ }^{\circledR}$ wrapped with the stretch film was 280.92 and 213.57 , respectively. The decrease in the gumminess for all the control samples depended also on the shrivelling of these fruits.

\section{Total phenolics content}

Fruits of Actinidia arguta are a rich source of phenolic compounds [Latocha et al., 2014]. Changes in total phenolics con-
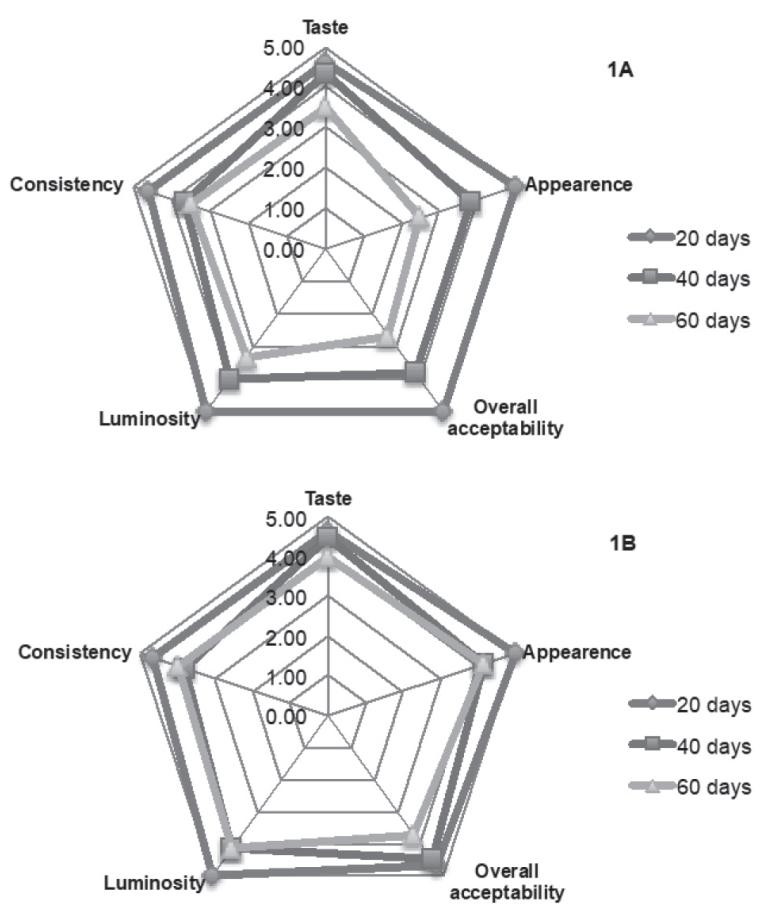

tent are reported in Table 2. It is possible to observe the difference among the two cultivars. According with previous studies [Latocha et al., 2014; Krupa et al., 2011], the cv. Hortgem Tahi ${ }^{\circledR}$ showed a higher total phenolics content when compared to Hortgem Rua ${ }^{\circledR}$. For both cultivars, the total phenolics content was increasing with the time of storage and it was not possible to observe the effect of the stretch wrap film on the regular evolution of these bioactive compounds in the samples.
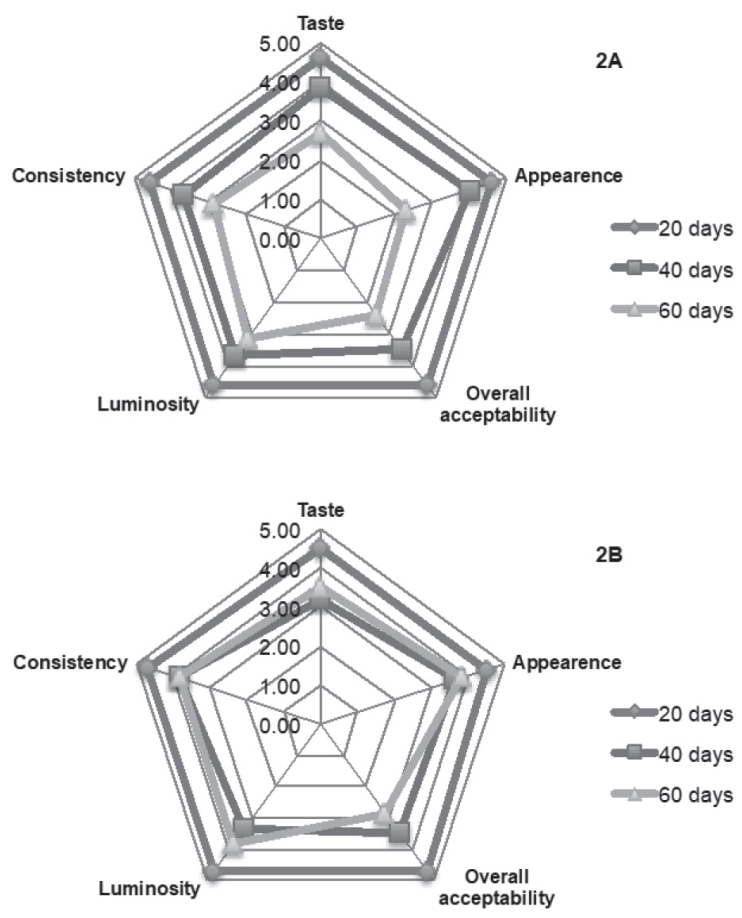

FIGURE 3. Sensory analysis of control and wrapped kiwifruits of Hortgem Rua ${ }^{\circledast}$ (respectively 1A and 2A) and Hortgem Tahi ${ }^{\circledR}$ (1B and 2B) cultivars stored up to 60 days in the warehouse. 


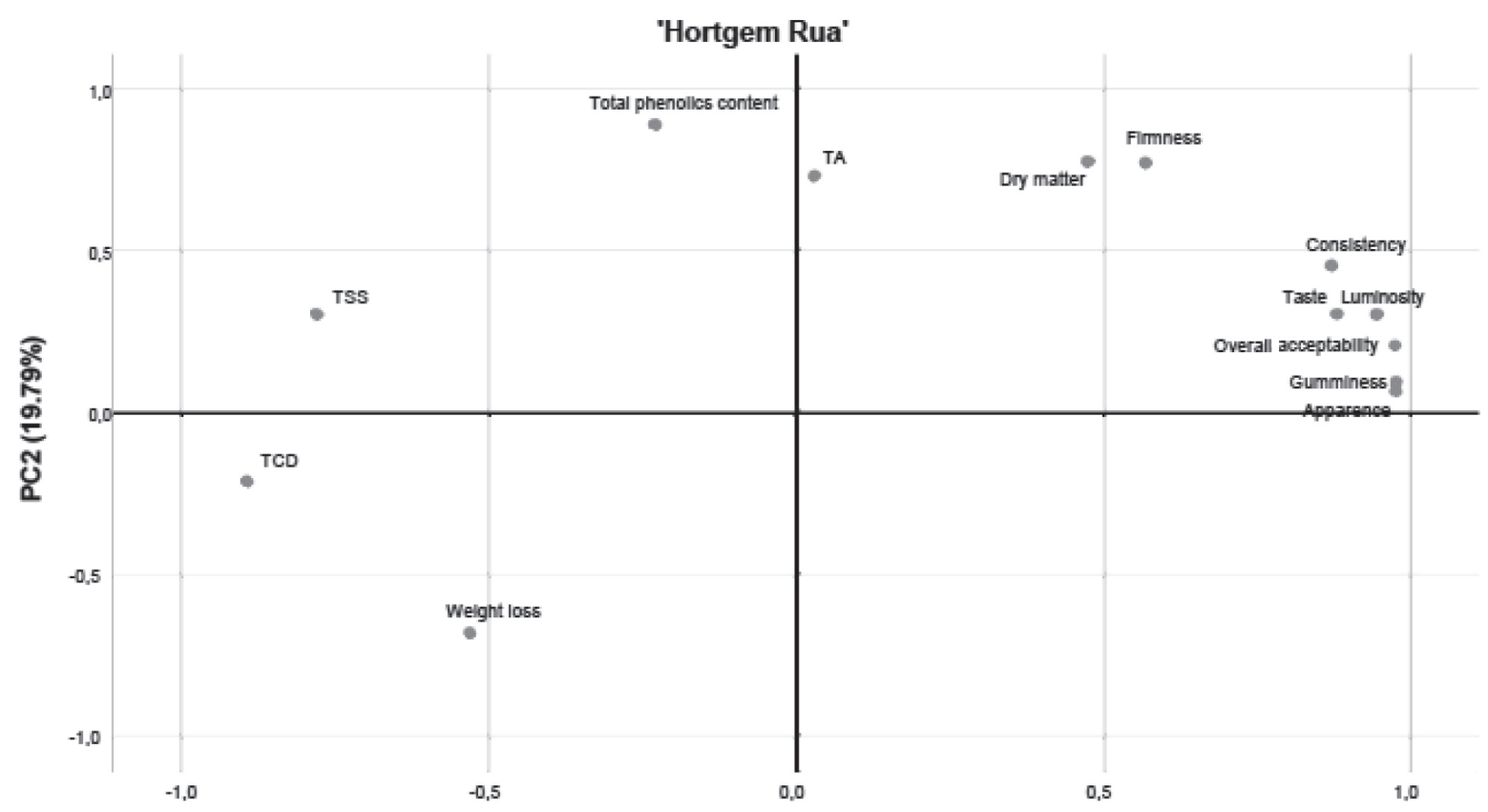

PC1 (65.94\%)

FIGURE 4. PCA of all parameters analyzed for kiwifruits of 'Hortgem Rua' ${ }^{\circledR}$ cultivar.

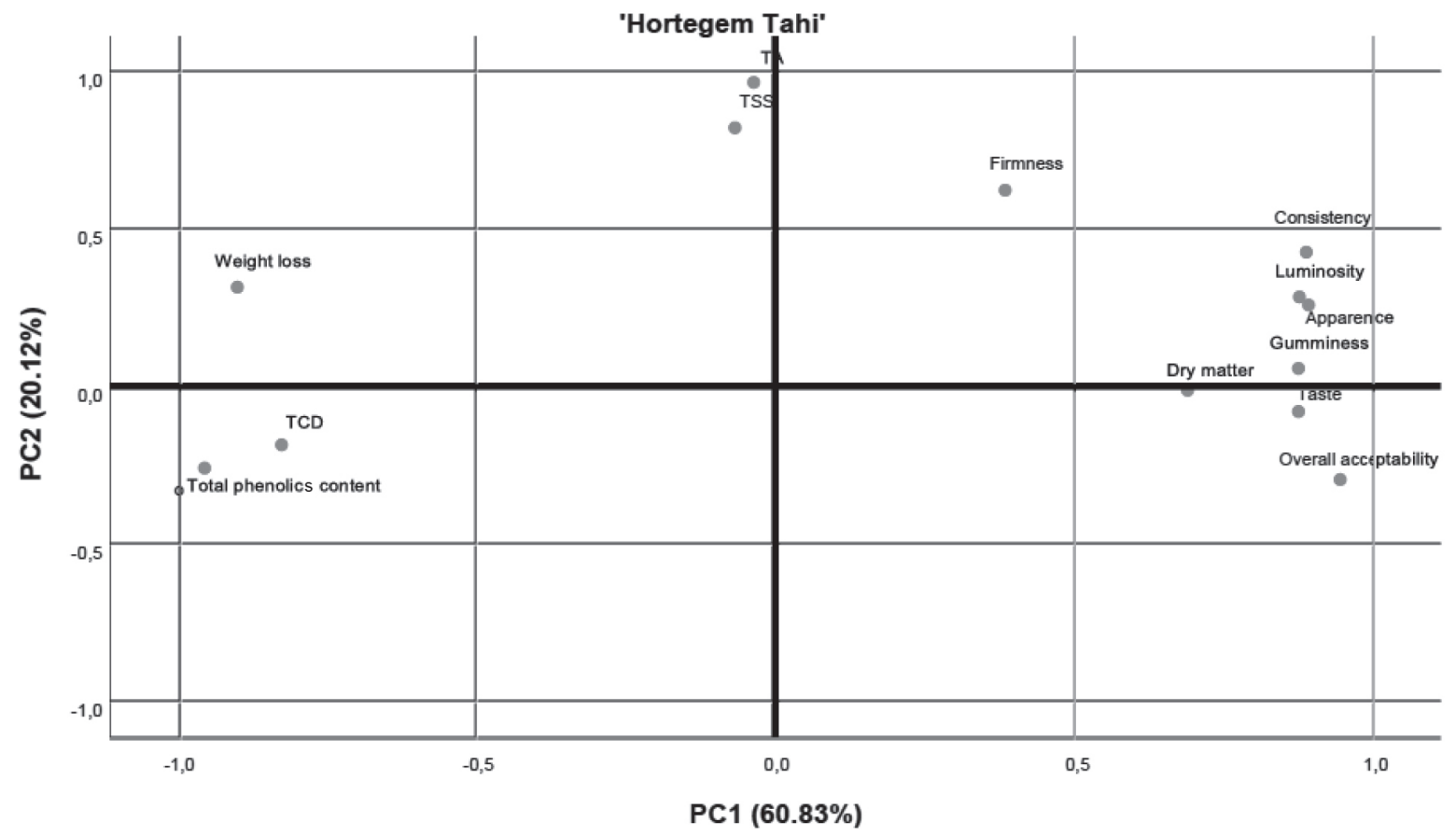

FIGURE 5. PCA of all parameters analyzed for 'Hortgem Tahi ${ }^{\circledR}$ 'cultivar.

\section{Sensory evaluation}

To support the instrumental measurements of quality, the sensory evaluation was conducted by the panellists in order to judge the overall quality of baby kiwifruits in terms of consumers' point of view. The overall sensory quality scores of samples of Hortgem Rua ${ }^{\circledR}$ and Hortgem Tahi ${ }^{\circledR}$ fruits (Figure 3) decreased successively when the storage time elapsed, achieving the lowest score profile after 60 days. Fruits of both of cultivars wrapped with the stretch film maintained the best overall quality, especially in terms of fruit luminosity, consistency, and taste. The sensory quality of the control samples of both cultivars diminished (which reduced their marketability) due to the reduction in freshness as a consequence of severe water loss (Figure 1). According to Garcìa-Ramos et al. [2003], the cultivar Hortgem Tahi ${ }^{\circledR}$ has a strong flavor and is appreciated more for the taste when compared to Hortgem Rua ${ }^{\circledR}$. 


\section{PCA}

Principal component analysis (PCA) was carried out on the correlation matrix produced from the quality parameters and the scores of the sensory analysis of baby kiwifruits of both cultivars stored. The PCA plots for the cultivar Hortgem Rua ${ }^{\circledR}$ and Hortgem Tahi ${ }^{\circledR}$ are reported in Figures 4 and 5, respectively. The cumulative variance contribution of all the principal components was $85.73 \%$ for the cv. Hortgem Rua $^{\circledR}$ which contributed most to the first (PC1) and the second (PC2) principal component $(65.94 \%$ and $19.79 \%$ respectively). In the case of the cv. Hortgem Tahi ${ }^{\circledR}$, the cumulative variance contribution of all the principal components was $81.04 \%$ (60.83\% for the PC1 and $20.21 \%$ for the PC2, respectively). For Hortgem Rua ${ }^{\circledR}$, the PC1 was described by the gumminess, the weight loss, and all the parameters considered in the sensory evaluation. For the Hortgem Tahi ${ }^{\circledR}$, the dry matter, gumminess, total phenolics content, and all the sensory parameters explained the PC1. As can be seen, it is possible to affirm that the textural parameter and the sensory evaluation attributes of the two cultivars belonged to the PC1. This shows how the external judgement is the driver of the consumer acceptance of the baby kiwifruits according to previous studies on Actinidia arguta [Latocha et al., 2011].

\section{CONCLUSION}

The short storage life of berry fruits (Actinidia arguta) is a critical point for their marketability, but a simple storage tool in the warehouse can be employed to support the economic sustainability of the storage process. The post-harvest management of these fruits can follow the berries supply-chain, thus using a stretch wrap film for the pallet storage could be a promising solution to maintain the quality of fruits for a long time. The baby kiwifruits represent a new product in the commercial channel of distribution and are particularly appreciated for the edibility of the whole fruit. Because of the fruits external sensitivity, the storage management in the warehouse is fundamental. Samples of Hortgem Tahi ${ }^{\circledR}$ and Hortgem Rua ${ }^{\circledR}$ fruits stored for up to 60 days with the stretch wrap film have maintained good quality characteristics when compared to the control samples, especially in terms of weight loss and textural properties. The firmness, gumminess, and sensory attributes have the greatest impact on consumer acceptance of the baby kiwifruits. Improving the chain value of these fruits could be a promising choice for the storage in the mini pallet material from the green chemistry as experimentally made for other species.

\section{ACKNOWLEDGEMENTS}

We would like to thank all of the producers, professionals, operators, colleagues and collaborators who actively participated in the research project.

\section{FUNDING SOURCE}

Research developed into the program ALTA FORMAZIONE IN APPRENDISTATO 2011-2013. Regione Piemonte (Art. 50-D. Lgs. N. 276/2003 s.m.i.).

\section{REFERENCES}

1. Alexandre, E.M., Brandão, T.R., Silva, C.L. (2012). Efficacy of non-thermal technologies and sanitizer solutions on microbial load reduction and quality retention of strawberries. Journal of Food Engineering, 108(3), 417-426.

2. Allegra, A., Sortino, G., Inglese, P., Settanni, L., Todaro, A., Gallotta, A. (2017). The effectiveness of Opuntia ficus-indica mucilage edible coating on post-harvest maintenance of 'Dottato' fig (Ficus carica L.) fruit. Food Packaging and Shelf Life, 12, 135-141.

3. Almenar, E., Del-Valle, V., Hernández-Muñoz, P., Lagarón, J.M., Catalá, R., Gavara, R. (2007). Equilibrium modified atmosphere packaging of wild strawberries. Journal of the Science and Food Agriculture, 87(10), 1931-1939.

4. Baudino, C., Giuggioli, N.R., Briano, R., Massaglia, S., Peano, C. (2017). Integrated methodologies (SWOT, TOWS, LCA) for improving production chains and environmental sustainability of kiwifruit and baby kiwi in Italy. Sustainability 9, art.no. 1621.

5. Bouchery, Y., Corbett, C.J., Fransoo, J.C., Tan, T. (2017). Introduction. In Y. Bouchery, C.J. Corbett, J.C. Fransoo, T. Tan (Eds.) Sustainable Supply Chains. vol. 4. Springer Nature Switzerland AG, pp. 1-12.

6. Briano, R., Giuggioli, N.R., Girgenti, V., Peano, C. (2015). Biodegradable and compostable film and modified atmosphere packaging in postharvest supply chain of raspberry fruit (cv. Grandeur). Journal of Food Processing and Preservation, 39(6), 2061-2073.

7. Briano, R., Peano, C., Giuggioli, N.R. (2017). The effects of the "green passive MAP" on the evolution on the gaseous and quality parameters in strawberries. Emirate Journal of Food and Agriculture, 29(3), 1-8.

8. DeEll, J.R. (2002). Modified atmospheres for berry crops. Ohio State University Extension Newsletter, 6, 27.

9. Fisk, C.L., Silver, A.A., Strik, B.C., Zhao, Y.X. (2008). Postharvest quality of hardy kiwifruit (Actinidia arguta 'Ananasnaya') associated with packaging and storage conditions. Postharvest Biology and Technology, 47(3), 338-345.

10. Garcìa-Ramos, F.M, Ortiz-Caìavate, J., Ruiz-Altisent, M., Dez JFlores, L. Homer, I., Ch'vez, J.M. (2003). Development and implementation of an on-line impact sensor for firmness sensing of fruits. Journal of Food Enginerring, 58(1), 53-57.

11. Giuggioli, N.R., Girgenti, V., Baudino, C., Giacalone, G., Chiabrando, V. (2017). Prediction models for the softening of new commercial Actinidia cultivars. Journal of Food Processing and Preservation, 4l(6), art no. e 13245.

12. Harker, F.R., Carr, B.T., Lenjo, M., Macrae, E.A., Wismer, W.V., Marsh, K.B., Williams, M., White, A., Lund, C.M., Walker, S.B., Gunson, F.A., Pereira, R.B. (2009). Consumer liking for kiwifruit flavour: A meta-analysis of five studies on fruit quality. Food Quality Preferences, 20(1), 30-41.

13. Jordan, R.B., Walton, E.F., Klages, K.U., Seelye, R.J. (2000). Postharvest fruit density as an indicator of dry matter and ripened soluble solids of kiwifruit. Postharvest Biology and Technology, 20, 163-173.

14. Kaya, M., Česonienè, L., Daubaras, R., Leskauskaitė, D., Zabulione, D. (2016). Chitosan coating of red kiwifruit (Actinidia melanandra) for extending of the shelf life. International Journal of Biological Macromolecules, 85, 355-360. 
15. Krupa, T., Latocha, P., Liwińska, A. (2011). Changes of physicochemical quality, phenolics and vitamin $\mathrm{C}$ content in hardy kiwifruit (Actinidia arguta and its hybrid) during storage. Scientia Horticulturae, 130(2), 410-417.

16. Latocha, P., Jankowski, P., Radzanowska, J. (2011). Genotypic difference in postharvest characteristics of hardy kiwifruit (Actinidia arguta and its hybrids), as a new commercial crop Part I. Sensory profiling and physicochemical differences. Food Research International, 44, 1936-1945.

17. Latocha, P., Krupa, T., Jankowski, P., Radzanowska, J. (2014). Changes in postharvest physicochemical and sensory characteristics of hardy kiwifruit (Actinidia arguta and its hybrid) after cold storage under normal versus controlled atmosphere. Postharvest Biology and Technology, 88, 21-33.

18. Latocha, P., Wołosiak, R., Worobiej, E., Krupa, T. (2013). Clonal differences in antioxidant activity and bioactive constituents of hardy kiwifruit (Actinidia arguta) and its year to year variability. Journal of the Science and Food Agriculture, 93(6), 1412-1419.

19. Lim, S., Han, S.H., Kim, J., Lee, H.J., Lee, J.G., Lee, E.J. (2016). Inhibition of hardy kiwifruit (Actinidia aruguta) ripening by 1-methylcyclopropene during cold storage and anticancer properties of the fruit extract. Food Chemistry, 190, 150-157.

20. McGlone, V.A., Jordan, R.B., Seelye, R. Clark, C.J. (2003). Dry matter - a better predictor of the post-storage soluble solids in apples? Postharvest Biology and Technology, 28, 431-435.

21. McNeilage, M.A., Beatson, R.A., Macrae, E.A. (2003). Kiwi plant named "Hortgem Tahi". Patent $N^{\circ}$ US PP13815P3 United States Plant Patent.

22. McNeilage, M.A., Beatson, R.A., Macrae, E.A. (2004). Kiwi plant named "Hortgem Rua". Patent N ${ }^{\circ}$ US PP14625 P3 United States Plant Patent.

23. McGuire, R.G. (1992). Reporting of objective color measurements. Horticultural Science, 27, 1254-1255.
24. Meilgaard, M.C., Carr, B.T., Civille, G.V. (2006). Sensory Evaluation Techniques. CRC Press. Taylor \& Francis Group, Parkway, NY, USA.

25. Montefiori, M., Comeskey, D.J., Wohlers, M., McGhie, T.K. (2009). Characterization and quantification of anthocyanins in red kiwifruit (Actinidia spp.). Journal of Agricultural and Food Chemistry, 57(15), 6856-6861.

26. Oh, S.B., Muneer, S., Kwack, Y.B., Shin, M.H., Kim, J.G. (2017). Characteristic of fruit development for optimal harvest date and postharvest storability in 'Skinny Green' baby kiwifruit. Scientia Horticulturae, 222, 57-61.

27. Peano, C., Briano, R., Giuggioli, N.R., Girgenti, V., Sottile, F. (2015). Evolution of qualitative characteristics during blueberry fruit storage in a modified atmosphere. Acta Horticulturae, 1071, 343-348.

28. Peano, C., Giuggioli, N.R., Girgenti, V., Palma, A., D’Aquino, S., Sottile, F. (2017). Effect of palletized MAP storage on the quality and nutritional compounds of the Japanese Plum cv. Angeleno (Prunus salicina Lindl.). Journal of Food Processing and Preservation, 41 (2), art.no. e12786.

29. Slinkard, K., Singleton, V.L. (1977). Total phenol analysis: automation and comparison with manual methods. American Journal of Enology and Viticulture, 28, 49-55.

30. Strik, B., Hummer, K. (2006). 'Ananasnaya' hardy kiwifruit. Journal of American Pomology Society, 60, 106-112.

31. Wang, Y., Xu, F., Feng, X., MacArthur, R.L. (2015). Modulation of Actinidia arguta fruit ripening by three ethylene biosynthesis inhibitors. Food Chemistry, 173, 405-413.

32. White, A., de Salva, H.N., Requejo-Tapia, C., Harker, F.R. (2005). Evaluation of softening characteristics of fruits from 14 species of Actinidia. Postharvest Biology and Technology, 35, 143-151.

Submitted: 29 May 2018. Revised: 11 September and 25 October 2018. Accepted: 16 November 2018. Published on-line: 22 January 2019. 